\title{
A produção escrita nas redes sociais e o uso das tecnologias em sala de aula: possibilidades de trabalho
}

\author{
Sergio Vale da Paixão \\ IFPR-Jacarezinho
}

Núbio Delanne Ferraz Mafra

UEL

\begin{abstract}
Resumo
Este texto aborda práticas pedagógicas nas aulas de língua portuguesa e suas interfaces com práticas de produção textual dos alunos na internet, tendo em vista a utilização por eles das redes sociais de relacionamento de forma frequente e fora do contexto escolar. Busca-se aproximar essas duas realidades, com vistas ao desenvolvimento das competências discursivas e o letramento discente. Esta pesquisa está ancorada em estudos sobre práticas escolares de leitura e escrita em consonância com a análise das tecnologias de informação e comunicação, somados aos fundamentos teóricos de pesquisas sobre interação. Serão apresentadas, no intuito de colaborar para as práticas pedagógicas dos professores, possibilidades de trabalho com a produção escrita no ambiente virtual de comunicação que possa colaborar para trabalhos com textos de qualidade produzidos pelos alunos no ambiente da escola, a partir dos contextos de leitura e produção das redes sociais.
\end{abstract}

Palavras-chave: produção de textos; letramento digital; interação.

\begin{abstract}
This report discusses pedagogical practices in Portuguese classes and their interfaces with students' textual production practices in the internet, taking into consideration the frequency with which the students use social networks outside the school context. We compare these two realities, with a view to the development of the students' discursive competence and literacy. This research is based on digital literacy studies that discuss social practices of reading and writing, in line with the new Information and Communication Technologies. The research also uses the theoretical foundations that come from interaction studies. With the intention of collaborating with teaching practices, this paper will suggest some possibilities for work with written text in the environment of virtual communication. The suggestions from this study will hopefully encourage students to write effective texts in the classroom, with the aid of the reading and writing contexts that they bring from social networks.
\end{abstract}

Keywords: text production; digital literacy; interaction. 


\section{INTRODUÇÃO}

A grande variedade de gêneros virtuais disponíveis na rede nos últimos tempos tem permitido que diferentes produções textuais, em diferentes suportes, sejam elaboradas pelos alunos, usuários frequentes das redes sociais de relacionamento. Dos recados em chats aos anúncios publicitários, as redes sociais são importantes suportes para que os alunos possam produzir seus textos com maior destreza e facilidade - deixando claro que não se tratam de atributos per si das redes sociais, mas de sua potencialidade pedagógica. Potencialidade que se vê reforçada quando observamos a maneira como os alunos têm utilizado esse espaço para fins de comunicação.

Inicialmente, vale dizer que defendemos com um tom otimista (Recuero, 2009) as produções escritas nas redes sociais e como recurso para aproximá-las de realidades sociais cada vez mais exigentes em relação à escrita, e assim, inclinamos nossa atenção principalmente para aquilo que entendemos como possibilidades de unir tais práticas, desenvolvidas na maioria das vezes de maneira natural e voluntária pelos alunos. Não estamos discriminando a escrita realizada nos moldes do papel e da caneta e muito menos defendendo a ideia de que o hipertexto venha ou deva substituir as práticas de produção escrita na escola. Nossa defesa pontua exatamente as condições de produção desse texto virtual que possibilita, dentro de seus limites, uma produção efetiva e que atenda as exigências comunicativas que se pretende com tal produção, o que geralmente não é o que acontece com os textos produzidos na escola.

Nosso interesse é criar "eventos escolares de letramento que provoquem a inserção do alunado em práticas letradas contemporâneas e, com isso, desenvolvam as competências/capacidades de leitura e escrita requeridas na atualidade" (Rojo, 2010:22). Temos procurado aproximar a utilização dos inúmeros artefatos disponíveis para fins de comunicação no intuito de preparar os alunos para que possam fazer uso da leitura e escrita em instâncias sociais que exijam do indivíduo uma postura atuante e adequada (Kleiman, 1995).

Embora utilizemos um material didático que está constantemente atualizado dentro daquilo que os PCNs (Brasil, 2008) têm orientado no que se refere ao devido uso das tecnologias, temos sentido a necessidade de somar forças com outras possibilidades de trabalho no intuito de colaborar de forma significativa com o processo de letramento múltiplo dos alunos que pode ser entendido "na perspectiva multicultural (multiletramentos), ou seja, 
diferentes culturas, nas diversas esferas, que terão práticas e textos em gêneros dessa esfera também diferenciados" (Rojo, 2009:111).

A questão que nos motiva é: em quê os sites de relacionamentos e os instrumentos de comunicação - tais como os computadores, aparelhos celulares, câmeras digitais, equipamentos de sons e outros - podem colaborar para o processo de ensino e aprendizagem dos alunos? Será que trazê-los para a sala de aula não fará com que o prazer em usá-los deixe de existir?

\section{FACEBOOK, VÍDEOS, E-MAILS, MSN}

Passamos agora a apresentar parte das atividades que acontecem frequentemente em nossa prática de sala de aula enquanto professor da disciplina de Língua Portuguesa e Produção de Textos na educação básica, no intuito de responder a essa questão. Procuramos sempre aproximar os conteúdos apresentados no material do aluno com práticas diferenciadas de utilização da linguagem nos espaços da internet para criarmos uma situação de diálogo entre a cultura escolar e aquela que os alunos estão acostumados a utilizar fora do ambiente da escola no espaço cibernético.

Ao iniciarmos o material do $2^{\circ}$ bimestre, em que o direcionamento era o de se trabalhar com as características do texto de opinião com alunos de um $2^{\circ}$ ano do Ensino Médio (EM), sentimos a necessidade de aproximar a rede social Facebook de uma turma de 29 alunos no sentido de mostrar as possibilidades de utilização dessas redes e a argumentação, frequentemente encontrada nesses ambientes, porém nem sempre usadas adequadamente pelos alunos. Assim, pedimos aos alunos que entrassem em nosso ambiente do Facebook e assistissem aos vídeos que seriam postados para eles para que pudessem produzir comentários “críticos, inteligentes e argumentativos", em relação àquilo que se apresentava nos vídeos. Este padrão ideal de comentários foi construído com base nas produções anteriores destes alunos, que se limitavam a enfocar elementos descritivos de qualquer proposta de produção textual, sem extrapolações e/ou inferências que representassem uma atitude autoral, de sujeito, perante a problemática apresentada. Portanto, trata-se de um "ideal" inserido no insipiente histórico de produção textual daquela turma. Com base nesta nova proposta, aos poucos os alunos foram inserindo seus comentários no campo aberto para esse fim e criando uma rede de discussões sobre o assunto de cada um dos vídeos "compartilhados" por nós nesse espaço.

Confiramos recortes do trabalho: 


\section{Imagem I}

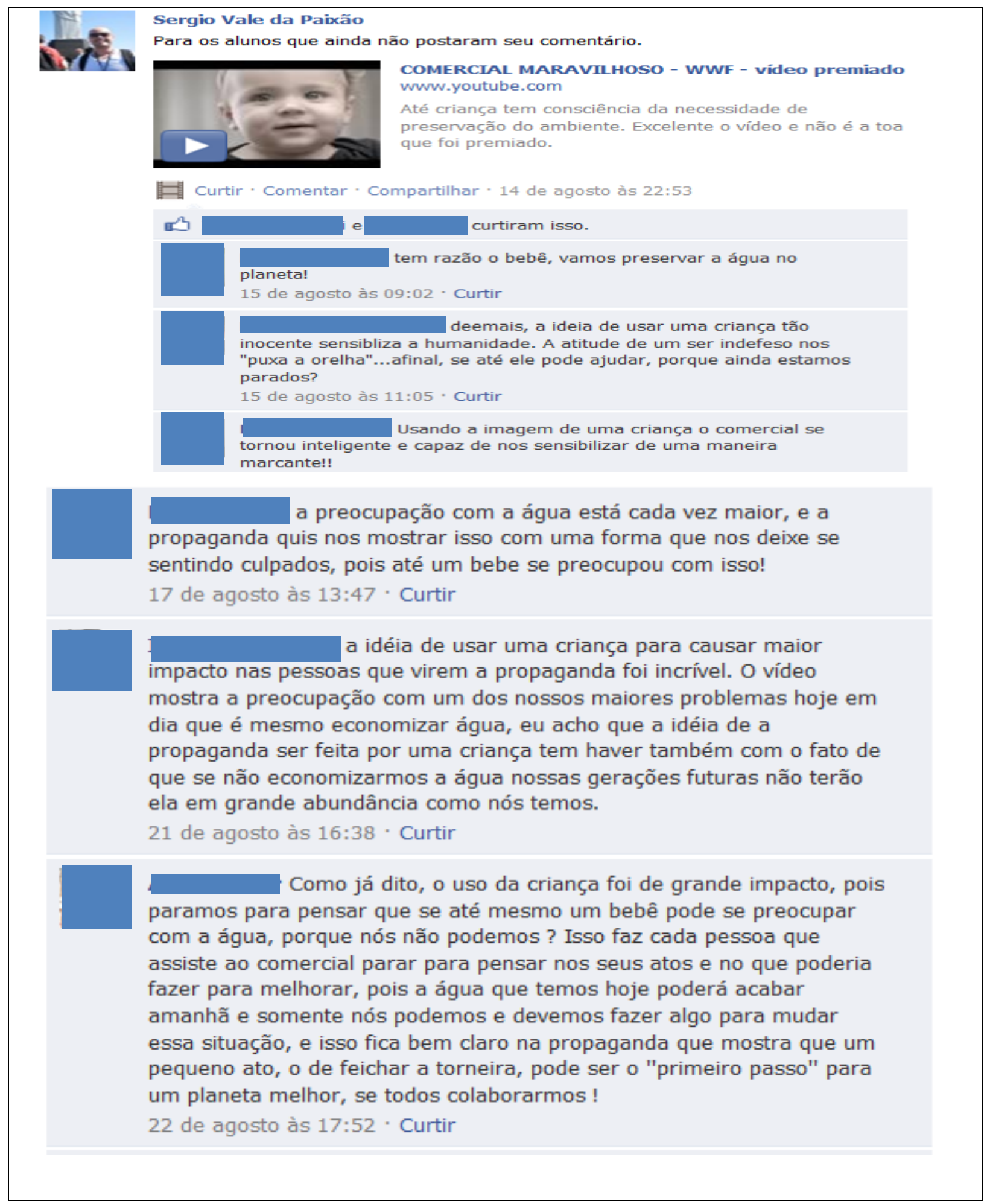

Surpreendemo-nos ao perceber que os alunos fizeram a atividade proposta em tempo hábil sem a necessidade de broncas, coerção e qualquer tipo de chantagem, o que é comum em situações de atividades de sala de aula ou como tarefa para casa - particularmente em 
aulas de produção de texto em língua portuguesa, quando a questão do "erro" costuma ganhar destaque.

$\mathrm{Na}$ imagem que ilustra parte daquilo que os alunos fizeram durante a atividade, utilizando-se do Facebook como suporte para sua produção, pode-se notar que os mesmos não abriram mão da linguagem permitida nesses ambientes de relacionamento, porém utilizaramna de forma adequada para atender a necessidade da situação - que era a de responder a uma solicitação do professor, o interlocutor real que havia solicitado a produção deles. Tal atividade foi fundamental para que os trabalhos posteriores que aconteceram em sala de aula com o texto de opinião e argumentativo pudessem ser compreendidos com maior clareza por parte dos alunos. Afinal estávamos analisando as próprias produções deles durante as aulas (Geraldi, 1984).

Da mesma forma, foi preciso trabalhar com o texto narrativo com uma turma do $1^{\circ}$ ano do EM, embora essa tipologia textual já fizesse parte da vida acadêmica deles desde as primeiras séries do ensino fundamental I. Era necessário dar uma nova "cara" ao conteúdo que, a partir de então, começaria a se configurar como uma exigência nos gêneros que passariam a ser lidos e produzidos por eles a partir daí. Caber-nos-ia então apresentar o texto narrativo de maneira mais lúdica e sensível aos olhos daqueles que, com muita frequência, têm contato com as características dessa tipologia textual em músicas que são ouvidas diariamente e em diferentes instrumentos de áudio.

Passamos então a trabalhar com o aparelho celular na sala de aula. Com a autorização da direção do colégio, passamos durante algumas aulas a compreender melhor a linguagem da música. Analisamos, compusemos, construímos e desconstruímos músicas, e, ao final, tínhamos como atividade produzir um texto narrativo com a utilização e montagem de fragmentos de músicas diferentes que pudessem, de alguma forma, fazer sentido quando de sua construção sintática. Quando solicitamos tal atividade aos alunos, deixamos clara a possibilidade de utilizar fragmentos de músicas de diferentes sons e ritmos e de cantores diferentes.

O resultado da atividade mostrou produções criativas e autênticas que puderam, dentro das condições de produção estabelecidas anteriormente, apresentar de forma bastante pessoal a construção de um texto narrativo com as marcas características dessa tipologia textual, porém elaboradas de forma prazerosa e voluntária pelo aluno.

Vejamos dois exemplos do resultado desse trabalho: 


\section{Texto 1}

Doente de amor, preciso de um remédio que cure essa saudade, assim você me mata, porque a saudade é um bichinho que rói. Sem me controlar, eu te peço, volta... Sinto dentro do meu peito um fogo ardendo, então me traz o seu olhar e o sorriso perfeito, que hoje eu vou te amar daquele nosso jeito! To doidinho pra beijar a sua boca, tirar a sua roupa e te jogar no chão, mas se quiser tem que ser agora, depois não dá! Se eu perder esse trem que sai agora às onze horas, só amanhã de manhã!

Pensando bem, então fica assim, a gente se encontra em outra ocasião. Se não agora, depois, não importa. Foi você quem falou que a paixão acabou. Por increça que parível, meu bem, você não é insubstituível. Enquanto eu te amava e estava sempre ao seu dispor, te valorizava, mas você nunca me deu valor... Amar assim? Melhor o fim do que ter o seu amor por piedade.

Boate azul - Bruno e Marrone

Efeitos - Cristiano Araújo part. esp. Jorge e Mateus

Ai, se eu te pego - Michel Teló

Saudade que rói - Henrique e Diego

$[\ldots]$

\section{Texto 2}

Histórias, nossas histórias...

Eu tinha apenas oito anos quando nós nos conhecemos.

Cresci longe da minha menininha, eu nunca esqueci a minha menininha.

É por isso que por você eu bebo o mar de canudinho e atravesso o pólo norte de shortinho.

Mas amigo... Eu beijei sua mulher, eu saí com sua mulher!

Só que a Bruna não da mais, agora é de amigo meu.

E agora vamo mexe, não importa quem vai ser,

Eu vou zoar, regaçar, vou chorar, vou beber

E se eu virar um cachaceiro e depois dormir na rua é porque eu to xonado, infeliz, disputado e a saudade

continua...

Porque segunda feira eu vou pro bar, terça feira eu vou também, beber, beber, beber.

Até que mudei os meus conceitos, me valorizei.

Dei a volta por cima e apresentei a minha nova namorada.

Ela é diferente, ela é engraçada, é inteligente e também é bem-humorada.

Adoro quando ela chega toda entusiasmada, cheia de carisma da rapaziada, mulher sem frescura, sempre toma

uma gelada, o assunto é futebol e ela ta atualizada.

Valeu!

Dias de luta, dias de glória - Charlie Brown Jr

Minha juventude - Mr Gyn

Menininha - Tchê Garotos

$[\ldots]$

Minha nova namorada - Marcos e Belutti

Ela é - Jeito Moleque

Valeu - Exaltasamba

As posteriores atividades que foram desenvolvidas a partir desse trabalho inicial - em que utilizamos a linguagem musical e o instrumento celular em sala de aula no intuito de resgatar músicas e sons que pudessem vir acrescentar em nosso trabalho - foram fundamentais para os trabalhos com outros textos que passamos a trabalhar a partir desse momento, que nos ajudaram a compreender na prática e de forma tranquila como se configura uma produção narrativa com suas características e peculiaridades. 
Prova concreta de que os alunos realmente gostaram e participaram com afinco da aula foi uma postagem realizada por um aluno logo ao chegar em casa, o que nos serve também como avaliação do trabalho que realizamos.

\section{Imagem II}

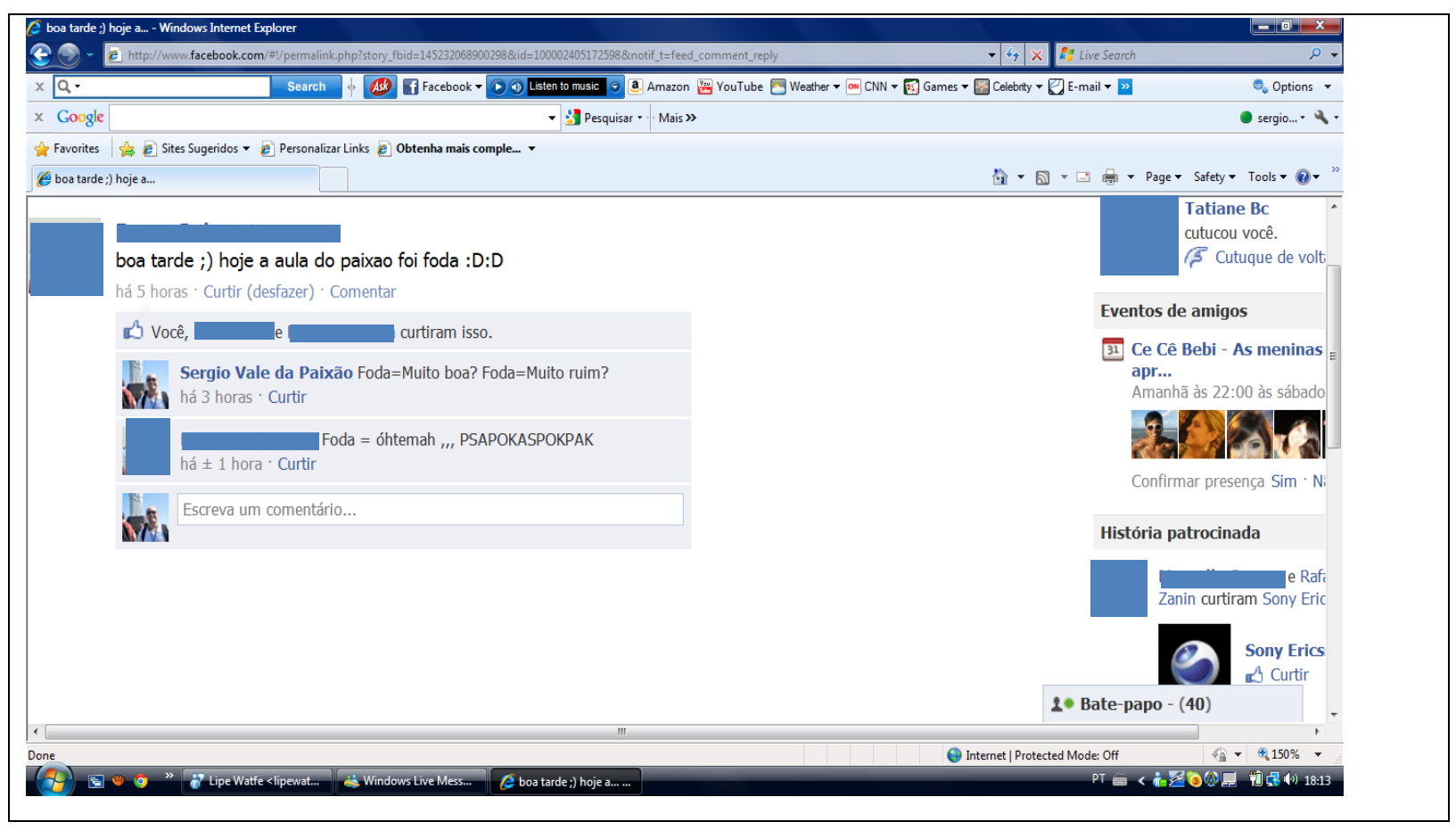

Na postagem, o aluno comenta:

Boa tarde;) hoje a aula do paixão foi foda $: D: D$.

O aluno faz referência utilizando nosso sobrenome "Paixão".

Curiosos, no sentido de entender o que ele queria dizer com a expressão utilizada, perguntamos ao aluno:

\section{Foda $=$ Muito boa? Foda= Muito Ruim:}

A partir daí obtivemos a seguinte resposta:

\section{Foda $=$ óhtemah... PSAPOKASPOKPAK}

A resposta nos faz observar que, dentro da linguagem utilizada por ele de forma bastante convencional do espaço cibernético, com seus excessos e abreviações, bem como 
com letras que simbolizam o riso, o aluno pode demonstrar sua apreciação no que diz respeito ao trabalho.

Outra situação que vale a pena destacar foi quando o gênero Anúncio Publicitário foi trabalhado em sala de aula, conforme sugeria o material didático. Esta atividade despertou nos alunos, que já conhecem nossa prática constante com as novas tecnologias em sala de aula, o desejo de elaborar alguns vídeos que pudessem registrar um pouco daquilo que havíamos estudado em sala de aula acerca do gênero. Dessa forma, e com uma postura bastante autônoma, os próprios alunos se organizaram em grupos e começaram a elaborar seus anúncios que em breve transformariam em pequenos vídeos que seriam apreciados pelos colegas na escola. O mais interessante foi que os próprios alunos "ministraram aulas" de montagem de vídeos, porquanto se dispuseram a apresentar aos seus colegas os mecanismos e instrumentos necessários para a elaboração das produções utilizando recursos simples, como o celular, computador e músicas. ${ }^{1}$

A produção do texto escrito com o gênero e-mail também foi uma das atividades que propusemos trabalhar com alunos de uma $7^{\mathrm{a}}$ série (nomenclatura antiga). Não vinculadas com o material didático, mas motivados pela falta de habilidade desses alunos em comunicação via endereços eletrônicos, propusemos orientá-los em prol de textos mais organizados e com conteúdos que atendessem a necessidade comunicativa de determinadas exigências pessoais.

Criamos então situações em que os alunos tivessem que assistir alguns vídeos no Youtube e, após a apreciação, enviassem, ao professor e aos colegas, comentários críticos sobre o vídeo em que pudessem apresentar seu ponto de vista sobre o conteúdo do que havia sido assistido. No e-mail, pedimos que os alunos anexassem o link para que os demais pudessem acessar.

Nessa atividade, pudemos observar que muitos desses alunos não sabem utilizar adequadamente instrumentos de comunicação básicos como o e-mail e sentimos o tamanho de nossa responsabilidade nesse sentido, já que trabalhamos com a disciplina de produção de textos numa perspectiva interacionista. Com uma maior dificuldade, pois tivemos que dispensar maior tempo para orientar os alunos nessa prática de produção escrita, pudemos reorganizar algumas práticas convencionais da linguagem utilizada nesse ambiente e permitir a compreensão de que as linguagens no espaço cibernético são flexíveis e que atendem as necessidade da comunicação e dos interlocutores desse texto.

\footnotetext{
${ }^{1}$ Os links a seguir remetem a parte dos três vídeos elaborados pela turma, em que eles mesmos foram os protagonistas: www.youtube.com/watch?v=izf42YZ9c2A, http://www.youtube.com/watch? $\mathrm{v}=\mathrm{aZb}$ - 4 bod0KD $\mathrm{e}$ www.youtube.com/watch?v=ctJRDr1xUfk.
} 
Vejamos uma produção realizada nessa perspectiva e que passou por algumas revisões e reorganizações pelo próprio aluno, com auxílio do professor:

\section{Texto 3 \\ Olá Sérgio, como vai? \\ É a Júlia que está falando aqui, só para constar.}

Bem, eu resolvi ver um vídeo chamado Nyan Cat, um meme recente da internet, do ano de 2011 ainda. Um meme é tudo aquilo que surge na internet e faz sucesso, de exemplos tem: O Rage, All your base are belong to us, Ievan polka, ORLY? Entre outros.

$\mathrm{O}$ vídeo apesar de parecer bem inocente e infantil, na verdade esconde uma coisa. A mistura de cores, movimentos rápidos, música e pixels fazem desse vídeo um vídeo alucinógeno!

Sim, o Nyan Cat na verdade é um vídeo de drogas virtuais. Muitas pessoas podem até ter epilepsia assistindo ele. Os sintomas variam entre dor de cabeça, enjôo, tontura ou até mesmo alucinações visuais, como o 'distorcimento' ( Essa palavra existe? ) da realidade. O interessante é que quando isso prende nossa atenção, os efeitos são maiores.

De princípio, não dá pra suspeitar que esse gatinho que solta um arco íris pela bunda é algo que mexe com nossa mente.

Eu achei muito interessante que, uma coisa que parece tão boba pode ser na verdade algo para nos deixar assim. Esse vídeo me dá no máximo dor de cabeça e tontura, me deixando num estado digno de drogas. O Nyan cat também é viciante, a música gruda em sua cabeça e você não quer parar de ver esse gatinho correndo, motivos? Sei lá, só sei que vicia pra caramba, e isso faz dele uma verdadeira droga virtual.

Link: http://www.youtube.com/watch?v=QH2-TGUlwu4

Abraços, e tente não ter um ataque epilético. Ass : Júlia

Vale destacar que outros trabalhos são possíveis de serem desenvolvidos e que ainda farão parte de nossa prática como formadores de cidadãos participativos em uma sociedade de múltiplos letramentos. Consideramos o momento tecnológico em que estamos vivendo uma rica possibilidade para o aprendizado de línguas, inclusive as estrangeiras. É importante também observar as inúmeras produções realizadas pelos alunos no espaço do MSN em que o usuário deve inserir seu nome ou apelido e que os mesmos estão inserindo fragmentos de música e de textos em outros idiomas. Apresentamos alguns recortes retirados desse suporte, MSN, dos nossos alunos:

\section{Imagem III}

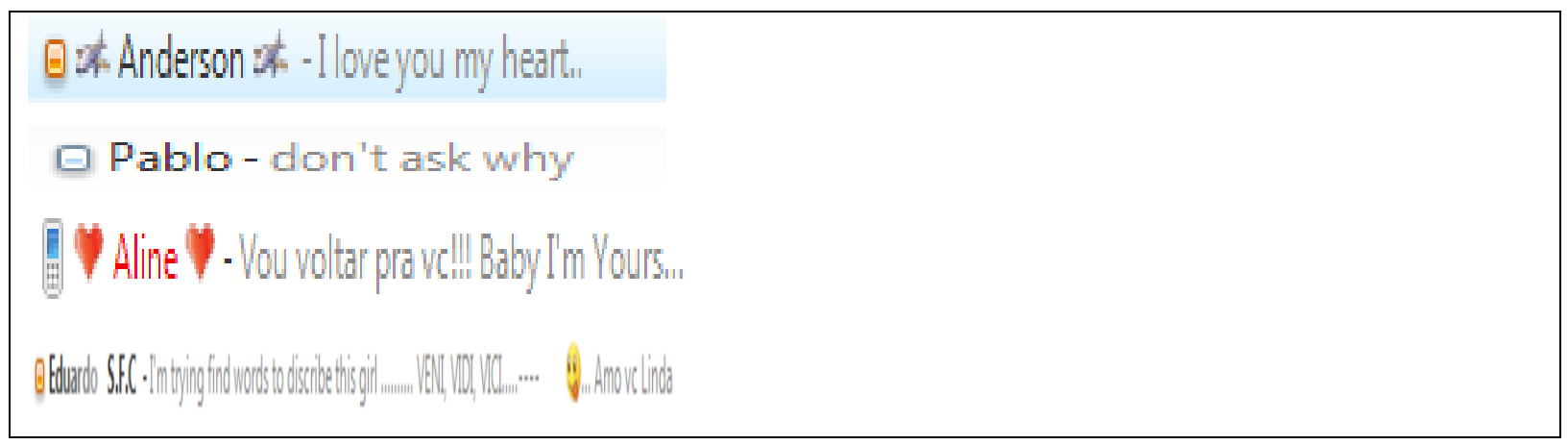




\section{Qth-I'Im going, and I'm leaving you belind,}

Nossos trabalhos, utilizando as redes sociais de comunicação na internet e os instrumentos para esse fim, bem como uma constante prática de observação dos usos desses recursos pelos alunos, têm sempre encontrado motivação e fundamentação nas teorias que orientam e inclinam sua atenção para as práticas de letramentos múltiplos e para a perspectiva de inclusão social desses alunos (Rojo, 2009). Nosso desejo é sempre o de colaborar para uma postura mais autônoma dos alunos nas práticas sociais de uso da linguagem em seus mais diferentes contextos de uso, e de modo bastante significativo, diminuir a distância que tem estado cada vez mais presente no ensino e na aprendizagem, não só da língua portuguesa, mas em todo o processo de escolarização na educação básica, pois entendemos que "essas formas de produção textual abrem espaço para novas modalidades de comunicação e novas maneiras de socialização" (Souza, 2006:111).

\section{CONSIDERAÇÕES FINAIS}

Acreditamos que a aproximação das ferramentas de informação e comunicação, hoje já bastante presentes na escola, e o pleno letramento dos alunos, via escola, é uma prática urgente no contexto atual, para possibilitarmos um melhor engajamento do indivíduo na sociedade e uma formação crítica de suas práticas sociais em um contexto cada vez mais digital, em que linguagens das mais váriadas possíveis são disponíveis para utilização dos usuários.

A sala de aula precisa "entrar em sintonia com as mídias disponíveis no mundo das comunicações, para que não fique estranha aos aprendizes, pouco interessante ou mesmo incoerente". (Ribeiro, 2006:89). Nossa defesa é em prol de que essas escritas, bem como os suportes que são utilizados para esse fim, como as redes sociais, por exemplo, possam fazer parte da sala de aula, e da escola, no intuito de somarmos forças para a construção de um indivíduo e, consequentemente, de uma sociedade mais crítica e atuante em que práticas de linguagem são demandadas. Acreditamos, assim como Braga (2010:4), que as comunidades e espaços virtuais

[...] além de aproximar grupos com interesses comuns, ampliaram os espaços e participações de duas formas distintas. Primeiro, elas permitem que indivíduos que não pertencem a determinados grupos sejam expostos a gêneros e discursos adotados por esses 
grupos, dando lugar a aproximações e apropriações gradativas de tais gêneros e discursos. Em segundo lugar elas permitem que barreiras normalmente levantadas por fatores como gênero, raça, idade, aparência física, classe econômica sejam "ocultados" no ambiente virtual, possibilitando um maior contato e até interação entre diferenças sociais.

É nesse sentido que debruçamos nossa total atenção à aproximação dessas possibilidades de trabalho com os instrumentos virtuais de informação e comunicação, para que, além de ajudar no processo de letramento do indivíduo, possamos colaborar para um crescimento social mais significativo.

\section{REFERÊNCIAS}

Braga, D. B. (2010). Tecnologia e participação social no processo de produção e consumo de bens culturais: novas possibilidades trazidas pelas práticas letradas digitais mediadas pela internet. Trabalhos de Linguística Aplicada. Campinas, 49 (2), 373-392, jul./dez.

Brasil. MEC/SEF (1998). Parâmetros curriculares nacionais: terceiro e quarto ciclos do ensino fundamental: língua portuguesa/Secretaria de Educação Fundamental. Brasília: $\mathrm{MEC} / \mathrm{SEF}$.

Geradi, J. W. (1984). Concepções de linguagem e ensino de português. In: (ed.). $O$ texto na sala de aula. 41-48. Cascavel: Assoeste.

Kleiman, A. B. (1995). Modelos de letramento e as práticas de alfabetização na escola. In: (ed.). Os significados do letramento: uma nova perspectiva sobre a prática social da escrita. 15-61. Campinas: Mercado de Letras.

Recuero, R. (2009). Redes sociais na internet. Porto Alegre: Sulina.

Ribeiro, A. E. (2006). Textos e hipertextos na sala de aula. In: C. V. Coscarelli (ed.). Novas tecnologias, novos textos, novas formas de pensar. 3. ed. 85-91. Belo Horizonte: Autêntica.

Rojo, R. (2009). Letramentos múltiplos, escola e inclusão social. São Paulo: Parábola.

. (2010). Alfabetização e letramentos múltiplos: como alfabetizar letrando? In: R.

Rojo \& E. O. Rangel (eds.). Língua Portuguesa: ensino fundamental. v. 19. 15-36. Brasília: Ministério da Educação, Secretaria de Educação Básica.

Souza, R. A. (2006). Comunicação mediada pelo computador: o caso do chat. In: In: C. V. Coscarelli (ed.). Novas tecnologias, novos textos, novas formas de pensar. 3. ed. 111-118. Belo Horizonte: Autêntica. 


\section{OS AUTORES}

Sergio Vale da Paixão é professor de Língua Portuguesa e Inglesa no Instituto Federal do Paraná (IFPR), campus Jacarezinho. Possui experiência na educação básica e no ensino superior, atuando como professor de Língua Portuguesa e Inglesa. Mestre em Estudos da Linguagem pela Universidade Estadual de Londrina (UEL), onde participa do Grupo de Pesquisa FELIP - Formação e Ensino em Língua Portuguesa (DGP/CNPq). Leciona em cursos de especialização e ministra palestras e cursos de capacitação para professores da educação básica com os seguintes temas: leitura e formação de leitores, produção textual e tecnologias na educação.

\section{E-mail: sergiovpaixao@ hotmail.com}

Núbio Delanne Ferraz Mafra é professor adjunto do Departamento de Letras Vernáculas e Clássicas da Universidade Estadual de Londrina (UEL), atuando na graduação e na pósgraduação e coordenando o Grupo de Pesquisa FELIP - Formação e Ensino em Língua Portuguesa (DGP/CNPq). Atualmente, desenvolve estágio pós-doutoral em Linguística Aplicada na Universidade Federal de Minas Gerais (UFMG). Integrante do GT Linguagem e Tecnologias da Associação Nacional de Pós-Graduação e Pesquisa em Letras e Linguística (ANPOLL) possui experiência na área de Linguagem e Educação, abordando principalmente os seguintes temas: estudos do letramento, ensino de língua portuguesa e formação de professores.

E-mail: nubiomafra@yahoo.com.br 